\title{
Does vitamin fortification affect light oxidation in fluid skim milk?
}

\author{
A. N. Schiano, ${ }^{1}$ Y. Jo, ${ }^{1}$ D. M. Barbano, ${ }^{2}$ and M. A. Drake ${ }^{1 *}$ \\ ${ }^{1}$ Department of Food, Bioprocessing and Nutrition Sciences, Southeast Dairy Foods Research Center, North Carolina State University, \\ Raleigh 27695 \\ ${ }^{2}$ Department of Food Science, Northeast Dairy Foods Research Center, Cornell University, Ithaca, NY 14853
}

\begin{abstract}
Off-flavors in milk related to light oxidation form due to photoxidation of native riboflavin and tetrapyrroles, resulting in an array of lipid oxidation compounds. Recent work has established that fortification with waterdispersible vitamin A can result in off-flavors in fluid skim milk caused by vitamin A degradation products in the vitamin premix. The objective of this study was to determine the role of vitamin fortification on light oxidation of high temperature, short time pasteurized fluid skim milk. First, the aroma profiles and aromaactive volatile compounds in light-exposed vitamin premixes were determined by exposing the premixes to fluorescent (FL) or light-emitting diode (LED) light at $2,000 \mathrm{~lx}$ at $4^{\circ} \mathrm{C}$ for $0,2,4,8$, or $24 \mathrm{~h}$. A trained panel (n $=6$ ) documented aroma profiles of each vitamin premix at each time point. Headspace solid-phase microextraction followed by gas chromatography-olfactometry and gas chromatography-mass spectrometry (GC-MS) were performed to characterize aroma-active compounds in light-exposed vitamin premixes. In the second experiment, commercial vitamin premixes (vitamin A and vitamin $\mathrm{D}$ in oil and water matrices) were used to fortify skim milk (vitamin A: 3,000 IU/946 mL; vitamin D: $600 \mathrm{IU} / 946 \mathrm{~mL}$ ). Skim milk was pasteurized, homogenized, and packaged in 946-mL high-density polyethylene jugs. Milks were exposed to FL or LED light at 2,000 lx at $4^{\circ} \mathrm{C}$ for $4,12,24$, or $48 \mathrm{~h}$. Controls with and without vitamins and light shielding were included. Riboflavin and vitamin A and D degradation were quantified via ultra-high-performance liquid chromatography. A trained panel $(\mathrm{n}=8)$ documented sensory profiles of milks at each time point. Lipid oxidation volatile compounds were quantified via solid-phase microextraction with GC-MS. Vitamin degradation volatile compounds were quantified via solvent-assisted sorptive stir bar extraction with GC-MS. Riboflavin, vitamin $\mathrm{A}$, and vitamin $\mathrm{D}$ degradation were consistent
\end{abstract}

Received August 24, 2018.

Accepted January 22, 2019.

*Corresponding author: mdrake@ncsu.edu with that reported in previous studies. We found no effect of vitamin fortification on development of typical light oxidation-related off-flavors (cardboard and mushroom) or lipid oxidation-related volatiles (hexanal and heptanal). A perfumey/floral flavor was documented in the oil-based vitamin A-fortified milk, suggesting that light exposure affected the off-flavors contributed by water- versus oil-based vitamin fortification. These results show no evidence that vitamin fortification at current levels provides any protection against light oxidation-related off-flavors in fluid milk.

Key words: vitamin fortification, light oxidation, milk, flavor

\section{INTRODUCTION}

Fluid milk has long been an important food around the world, once comprising over $10 \%$ of American daily caloric intake (IDFA, 2016). However, fluid milk consumption in the United States has steadily declined over the past $50 \mathrm{yr}$ (IDFA, 2016). Current theories as to the declining popularity of milk include competition from other beverages as well as consumer dissatisfaction with flavor variability in milk (McCarthy et al., 2017a). Light oxidation and vitamin fortification are 2 such sources of flavor variability in milk.

Whole milk is a good source of vitamin A and of provitamin carotenoids such as $\beta$-carotene and lutein; however, as these compounds are insoluble in water, the overall vitamin content of milk decreases when whole milk is separated and standardized into skim or reduced fat milk (Rodriguez-Amaya, 2016). Skim and reduced fat milks are legally required to be fortified with vitamin A to be "nutritionally equivalent" to whole milk (DPC, 2001). Fortification with vitamin D, although not legally mandated in the United States, is common because of the historical precedent of preventing rickets in children by supplementing milk with vitamin D (Public Health Service, 1940). Today, vitamin A is typically added to milk as synthetic retinyl palmitate, whereas vitamin $\mathrm{D}$ is added as synthetic $\mathrm{D}_{3}$. Legally, fluid milk sold in the United States may contain from 100 to $150 \%$ of the amount of vitamins 
A and D declared on the label (PHS/FDA, 2015). These vitamins are available as commercial concentrates, which are typically added to fluid milk after standardization and before pasteurization (Yeh et al., 2017b). Concentrated vitamin premixes are available in 2 forms: oil-based and water-soluble (Yeh et al., 2017b). Yeh et al. (2017a) reported that when skim milk was fortified with water-dispersible (but not oil-based) vitamin A concentrate at levels close to the upper limit allowed by law [3,000 IU/946 mL (1 quart)], consumers could detect flavor differences between unfortified and fortified milks. Sensory evaluation by trained panelists confirmed that the vitamin A-related flavor in fortified milks was described as "carrot-like." Consumers were not able to distinguish between fortified and unfortified $2 \%$ milks or milks fortified with only vitamin $\mathrm{D}$. The atypical carrot off-flavor was attributed to vitamin A degradation compounds. Thus, vitamin fortification, particularly with water-dispersible vitamin A, may be a source of atypical flavors encountered in skim milk.

Light exposure, in contrast, is a well- and longestablished source of off-flavor formation in fluid milk. When milk is exposed to light, photochemical reactions are initiated by the absorption of light by light-sensitive compounds within the milk. Riboflavin is the primary photosensitizer in milk, although naturally occurring tetrapyrroles, including protoporphyrin IX, hematoporphyrin, and a chlorophyll a analog, also play a role in the development of light oxidized flavors (AiradoRodríguez et al., 2011). When light of particular wavelengths hits compounds sensitive to those wavelengths, the electrons in the photosensitive compounds become excited, which can result in photoxidation reactions occurring through formation of a free radical chain or by interactions with oxygen forming highly reactive singlet excited state oxygen (Min and Boff, 2002; Airado-Rodríguez et al., 2011). Both of these photosensitization reactions can occur simultaneously in milk, compete with each other, and lead to off-flavors, which are unpleasant to consumers (Bray et al., 1977; White and Bulthaus, 1982; Lee and Min, 2009; Wold et al., 2015; Martin et al., 2016; Potts et al., 2017; Chang and Dando, 2018). Light exposure reduces consumer acceptability of skim and reduced fat milks, making control of light oxidation-related off-flavors a key issue for the dairy industry (Walsh et al., 2015; Martin et al., 2016). Although packaging modifications such as opaque or light-blocking packaging may slow development of light oxidation-related off-flavors, consistent control of these off-flavors remains challenging (Johnson et al., 2015).

Not all light-absorbing compounds in fluid milk are photosensitizers. Fortified retinyl palmitate and naturally occurring carotenoids such as $\beta$-carotene can act as antioxidants, scavenging free radicals and perhaps affecting light oxidation in fluid milk (Palace et al., 1999). Carotenoids can halt free radical reactions in several ways. Most of the time, excitation energy from singlet oxygen can transfer to the carotenoid and dissipate as heat (Palace et al., 1999). However, if the singlet oxygen free radical is stabilized by the polyene chain of the carotenoid, the carotenoid will cleave at an unpredictable carbon along the polyene chain, destroying the vitamin and resulting in the potential development of aromatic vitamin degradation compounds (Palace et al., 1999). Light exposure causes significant destruction of vitamin A and other carotenoid compounds in fluid milk. Whited et al. (2002) measured significant vitamin A degradation after just $2 \mathrm{~h}$ when skim or reduced fat milk was exposed to fluorescent light at 2,000 or 1,000 lx.

The role of volatile vitamin degradation compounds on the flavor of light-oxidized fluid milk has not been fully investigated. Previous research has shown that the addition of the natural antioxidants ascorbic acid and $\alpha$-tocopherol delayed the onset of light-induced off-flavor formation and the formation of volatile compounds associated with light oxidation in light-exposed milk, but neither retinyl palmitate or tocopheryl acetate added to whole milk successfully prevented off-flavor development with light exposure (van Aardt et al., 2005; Gutierrez et al., 2018). However, the antioxidant potential of fortified vitamins in fluid fortified skim milk has not been studied. Vitamin fortification and light exposure are known sources of off-flavors in milk, but possible interactions between vitamin fortification and light exposure have not been evaluated in milk fortified according to commercial practices. The objective of this study was to determine the role of vitamin fortification on light oxidation of fluid HTST pasteurized skim milk.

\section{MATERIALS AND METHODS}

\section{Experimental Overview}

Two experiments were included in this study. Experiment 1 was a preliminary experiment to determine the sensory profiles and aroma-active volatile compounds in light-exposed vitamin premixes to determine whether additional aroma-active volatile compounds were generated by light exposure beyond those documented by Yeh et al. (2017a). For this preliminary objective, we performed descriptive analysis, headspace extraction, and identification of volatile compounds by GC-MS and gas chromatography-olfactometry (GC-O) on 4 different vitamin premixes (water-dispersible A palmitate, A palmitate in an oil matrix, water-dispersible $\mathrm{D}_{3}$, and $\mathrm{D}_{3}$ in an oil matrix) exposed to fluorescent (FL) 
or light-emitting diode (LED) light. The purpose of experiment 2 was to determine the possible effect of vitamin $\mathrm{A}$ and $\mathrm{D}$ fortification on light-oxidized flavor development in skim milk. For this objective, skim milk was fortified with 1 of the 4 vitamin premixes, HTST pasteurized, and exposed to FL or LED light. We evaluated skim milk because previous work on vitamin fortification demonstrated that skim milk was at highest risk for vitamin-related off-flavors and because fat plays a protective role in both vitamin degradation and light-oxidized flavor development (Gaylord et al., 1986; Yeh et al., 2017a). If vitamin fortification affects the off-flavor(s) produced by light exposure, it will likely be detected in skim milk. Descriptive analysis, vitamin analysis, and quantification of selected volatile compounds by GC-MS were conducted in light-exposed milks with and without added vitamins.

\section{Commercial Vitamin Premixes and Chemical Standards}

Duplicate lots of 4 commercial vitamin premixes (vitamin A palmitate and vitamin $\mathrm{D}_{3}$ ) in oil-based and water-dispersible matrices were used. All premixes were within $45 \mathrm{~d}$ of manufacture, with $>9$ mo of remaining shelf life and had been previously characterized (Yeh et al., 2017a). Upon arrival, samples were stored at room temperature in the dark until analysis. All chemical standards were obtained from Sigma-Aldrich (Milwaukee, WI). The vitamin A water-dispersible premix contained water, polysorbate 80 , vitamin A palmitate, citric acid, and sodium benzoate. The vitamin A in oil premix contained sunflower oil and vitamin A palmitate. The vitamin $\mathrm{D}$ water-dispersible premix contained water, propylene glycol, polysorbate 80 , and vitamin $\mathrm{D}_{3}$. The vitamin $\mathrm{D}$ in oil premix contained sunflower oil and vitamin $\mathrm{D}_{3}$.

\section{Construction of Light Box}

Two light boxes $(88 \times 57 \times 31 \mathrm{~cm})$ were constructed and covered with laser cloth (BK5 blackout fabric, ThorLabs Inc., Newton, NJ) so that all ambient light was blocked from the boxes, as described by Brothersen et al. (2016). One box was fitted with fluorescent lights at 2,000 lx (3500 K, General Electric, Boston, MA) and the other was fitted with LED refrigerator case strip lights at 2,000 lx (3500 K, International Light Technologies, Peabody, MA). Light intensities were verified from the literature (De Man, 1978; Whited et al., 2002) and by taking the light intensity values of commercial dairy cases at 10 stores in the Raleigh-Durham (North Carolina) area. A light intensity of approximately 2,000 $\mathrm{lx}$ is listed as the reference light intensity for vitamin A degradation in the Pasteurized Milk Ordinance (PHS/ FDA, 2015). The 2 boxes were placed in a walk-in refrigerator and held at $4^{\circ} \mathrm{C}$. The fluorescent light box was outfitted with a $17 \mathrm{~W}, 2300 \mathrm{rpm}$ reversible cooling fan (North American Cable Equipment Inc., West Chester, PA) to maintain a constant temperature $\left( \pm 1^{\circ} \mathrm{C}\right)$ inside the box. Temperature and lux values were continuously recorded inside the boxes with a datalogging probe (MSR Electronics GmbH, Seuzach, Switzerland).

\section{Experiment 1}

Light Exposure of Vitamin Premixes. The 4 vitamin premixes were exposed to FL or LED light in the previously described light boxes for $0,2,4,8$, or $24 \mathrm{~h}$ at $4^{\circ} \mathrm{C}$. Vitamin premix $(19 \mathrm{~mL})$ was added to clear $20-\mathrm{mL}$ glass vials (Microliter Analytical, Suwanee, GA), which were flushed for $10 \mathrm{~s}$ under nitrogen gas to minimize oxygen exposure before capping. Vials were covered with clear high-density polyethylene plastic milk jugs (S-19296, Uline, Pleasant Prairie, WI) to ensure that the wavelengths of light to which the premixes were exposed were representative of the wavelengths to which milk in commercial dairy cases would be exposed through plastic packaging used for fluid milk. This process was replicated twice.

Descriptive Analysis of Light-Exposed Vitamin Premixes. All sensory testing was deemed exempt by the North Carolina State University Institutional Review Board for human subjects. Ten-milliliter samples of light-exposed vitamin premixes were evaluated orthonasally in 60-mL lidded soufflé cups (Solo Cup Co., Champaign, IL) labeled with 3-digit blinding codes. Lidded cups were allowed to equilibrate at room temperature for $30 \mathrm{~min}$ before evaluation. Samples were evaluated by 6 panelists ( 4 women, 2 men, ages $22-49$ $\mathrm{yr}$ ), each of whom had more than $150 \mathrm{~h}$ of previous experience with the sensory analysis of food aromas and flavors using the Spectrum descriptive analysis method (Meilgaard et al., 2007). The lexicon for vitamin premixes developed by Yeh et al. (2017a) was applied. Each premix was evaluated by each panelist in duplicate in a randomized order. Compusense Cloud (Compusense, Inc., Guelph, ON, Canada) was used for data collection. Samples were evaluated by each panelist in 8 sessions across 2 d. No more than 10 samples were evaluated in each session with an enforced 2-min rest between samples. A minimum 30-min rest between sessions was enforced.

Headspace Extraction of Volatile Compounds from Light-Exposed Vitamin Premixes. Volatile compounds were extracted from vitamin premixes by headspace solid-phase microextraction (SPME) followed by GC-MS using the methods of Yeh et al. 
(2017a) with modifications. All injections were made on an Agilent 7820 GC with a 5975 MSD (Agilent Technologies Inc., Santa Clara, CA) with a ZB-Semivolatiles column $(5 \%$ phenyl-arylene stationary phase, $30 \mathrm{~m}$ long $\times 0.25 \mathrm{~mm}$ i.d. $\times 0.25 \mu \mathrm{m}$ film thickness, Zebron; Phenomenex, Torrance, CA). Volatile compounds were extracted using a CTC Analytics CombiPal Autosampler (Zwingen, Switzerland). Five milliliters of vitamin premix was added to $20-\mathrm{mL}$ amber glass SPME vials (Microliter Analytical) in triplicate. Vials were equilibrated for $25 \mathrm{~min}$ at $40^{\circ} \mathrm{C}$ with 4 -s pulses of 250 rpm agitation. A 1-cm SPME fiber (divinylbenzene/ carboxen/polydimethylsiloxane; Supelco, Bellefonte, PA) was used. The SPME fiber was exposed to the samples for $40 \mathrm{~min}$ at a depth of $3.1 \mathrm{~cm}$. The fiber was retracted and injected at $5.0 \mathrm{~cm}$ in the GC inlet for $5 \mathrm{~min}$. Scanning from 30 to $200 \mathrm{~m} / \mathrm{z}$ was performed to identify selected aroma-active compounds of interest, as described by Yeh et al. (2017a). Each vitamin premix was evaluated in triplicate.

$G C$-O. Headspace SPME followed by GC-O was performed to characterize aroma-active compounds in light-exposed vitamin premixes as described by Yeh et al. (2017a) with the modification of the use of a ZBSemivolatiles column $(30 \mathrm{~m}$ length $\times 0.25 \mathrm{~mm}$ i.d. $\times$ $0.25 \mu \mathrm{m}$ film thickness, Zebron; Phenomenex Inc.). Ten milliliters of vitamin concentrate was added to $40-\mathrm{mL}$ amber vials $(28 \times 98 \mathrm{~mm}$; Supelco Inc.) with a stir bar. The vials were heated at $40^{\circ} \mathrm{C}$ for 3 min with constant stirring. An SPME fiber (divinylbenzene/carboxen/ polydimethylsiloxane; Supelco Inc.) was exposed in each sample at $2 \mathrm{~cm}$ for $30 \mathrm{~min}$. The fiber was then injected on an Agilent 6850 GC-O flame-ionization detector equipped with an olfactometer port (Agilent Technologies Inc.). The $\mathrm{GC}$ method used an initial temperature of $40^{\circ} \mathrm{C}$ for $3 \mathrm{~min}$. The temperature was then increased at a rate of $10^{\circ} \mathrm{C} / \mathrm{min}$ to $150^{\circ} \mathrm{C}$, followed by $30^{\circ} \mathrm{C} / \mathrm{min}$ to $200^{\circ} \mathrm{C}$, and held for $5 \mathrm{~min}$. The flame-ionization detector sniffing port was held at $300^{\circ} \mathrm{C}$, with a helium carrier gas flow of $2 \mathrm{~mL} / \mathrm{min}$, and the port was supplied with humidified air at $30 \mathrm{~mL} / \mathrm{min}$. Each sample was evaluated in triplicate by 3 highly experienced sniffers (each with $>50 \mathrm{~h}$ of previous experience with GC-O), who recorded retention time, aroma character, and perceived intensity of each aroma event.

Compound Identification for Light-Exposed Vitamin Premixes. Retention indices, mass spectra, and odor properties of unknown compounds were compared with those of authentic standard compounds (Sigma-Aldrich) analyzed under identical conditions on GC-MS and GC-O. Tentative identifications were based from comparisons of the mass spectra of unknown compounds with those in the National Institute of Standards and Technology mass spectral database
(NIST MS Search 2.0, NIST/EPA/NIH Mass Spectral Library, http://webbook.nist.gov) or from matching retention index values of unknowns against those of authentic standards. To calculate retention indices, an alkane series $\left(\mathrm{C}_{8}-\mathrm{C}_{20}\right.$ Sigma-Aldrich) was used (Van Den Dool and Kratz, 1963).

\section{Experiment 2}

Pilot Plant Manufacture of Vitamin-Fortified Milk. The 4 vitamin premixes were used to fortify skim milk. Unfortified skim milk was also processed. Raw skim milk was obtained from the North Carolina State University Dairy Enterprise System (Raleigh). Raw milk proximate analyses included SCC (Somascope, Delta Instruments, Drachten, the Netherlands), coliform count, aerobic plate count, and fat and TS contents. Coliform and aerobic plate counts were conducted using standard methods (Wehr and Frank, 2004; method numbers 7.070 and 6.040, respectively) with Petrifilm plates (Coliform Count Plates and Aerobic Count Plates; 3M, St. Paul, MN). Plates were incubated at $32^{\circ} \mathrm{C}$ for $24 \mathrm{~h}$ before being counted. Fat and TS contents were measured using a Fourier-transform mid-infrared milk analyzer (LactoScope FTIR; Delta Instruments).

Vitamin premixes were added to the raw skim milk. Raw milks for each run were batched as follows: control with no vitamin addition, water-dispersible vitamin $\mathrm{A}$ at 3,000 IU/946 mL, oil-based vitamin $\mathrm{A}$ at 3,000 $\mathrm{IU} / 946 \mathrm{~mL}$, water-dispersible vitamin $\mathrm{D}$ at $600 \mathrm{IU} / 946$ $\mathrm{mL}$, and oil-based vitamin D at $600 \mathrm{IU} / 946 \mathrm{~mL}$. These fortification levels represent the maximum level of fortification for each vitamin allowable by the United States Food and Drug Administration (150\% of label claims for skim and reduced fat milks), thus representing a "worst case" scenario for flavor differences resulting from vitamin fortification (PHS/FDA, 2015). A Microthermics EHVH pasteurization unit (Microthermics, Raleigh, NC) with a 2-stage homogenizer (GEA Niro Soavi, Parma, Italy) was used to process the milks. Each batch was preheated to $60^{\circ} \mathrm{C}$, homogenized (first stage at $17.3 \mathrm{MPa}$ and second stage at 3.4 MPa), and pasteurized $\left(73^{\circ} \mathrm{C}\right.$ for $\left.15 \mathrm{~s}\right)$ before cooling to $10^{\circ} \mathrm{C}$. Final products were collected in $946-\mathrm{mL}$ high-density polyethylene milk jugs (S-19296, Uline) and then placed at $4^{\circ} \mathrm{C}$. Milks were tested for complete pasteurization by the alkaline phosphatase test (Wehr and Frank, 2004; method 14.060). Microbial quality of the pasteurized milk was evaluated using the methods described previously.

Exposure of Milks in Light Box. After a 24-h equilibration period at $4^{\circ} \mathrm{C}$, pasteurized fortified and unfortified milks were placed in the light boxes. The 
temperature in each light box and the light intensity at the surface of the milk jugs were continuously recorded with a datalogging probe (MSR Electronics $\mathrm{GmbH}$ ) to ensure that temperature and light intensity remained constant throughout the exposure period. Samples were removed after $4,12,24$, and $48 \mathrm{~h}$. Once removed, jugs were covered with laser cloth to prevent additional light exposure and stored at $4^{\circ} \mathrm{C}$ for the remainder of the 48-h exposure period. Control samples for the 4 fortified treatments and unfortified treatment were kept covered in laser cloth at $4^{\circ} \mathrm{C}$ during the entire exposure period to prevent any light exposure. After the 48-h exposure period, all milks were immediately prepared for descriptive sensory analysis. The remaining milk was transferred to $50-\mathrm{mL}$ vials (Fisher Scientific, Hampton, $\mathrm{NH}$ ) and immediately frozen at $-80^{\circ} \mathrm{C}$. Vitamin and volatile compound analyses were completed within 40 d. The entire experiment was replicated twice.

Vitamin $A$ and $D$ Analysis. Vitamin analysis was conducted in a laboratory with UV-filtered orange lighting to prevent light oxidation and destruction of vitamins during extraction and analysis. Vitamin analysis was conducted in accordance with the procedure published by Chen et al. (2015). A 15-mL test portion of fortified milk was added to a $250-\mathrm{mL}$ amber glass jar (Sigma-Aldrich) along with $10 \mathrm{~mL}$ of $50 \%$ (wt/wt) aqueous $\mathrm{KOH}$ (Sigma-Aldrich) and $20 \mathrm{~mL}$ of ethanol (Sigma-Aldrich) containing 2\% (wt/vol) pyrogallol (Sigma-Aldrich). Samples were saponified in a water bath held at $60^{\circ} \mathrm{C}$ for $2 \mathrm{~h}$ and mixed by inversion every $15 \mathrm{~min}$. Samples were extracted twice successively with $20 \%$ diethyl ether in hexane (vol/vol). Thirty milliliters of diethyl ether:hexane (solvent phase) was added to the saponified milk, which was allowed to settle, washed with a 50-mL aliquot of deionized water, mixed by inverting 8 times, and allowed to settle again. A $15-\mathrm{mL}$ aliquot of the solvent phase was transferred to a light-shielded beaker for each extraction. The collected solvent phase was transferred to a 125 -mL glass separatory funnel and washed with $50 \mathrm{~mL}$ of deionized water. A $10-\mathrm{mL}$ aliquot of the washed solvent was transferred to a 50-mL plastic centrifuge tube (Fisher Scientific), dried at room temperature under a nitrogen gas stream, and reconstituted in 15\% deionized water in methanol (vol/vol; Sigma-Aldrich) by sonicating for $5 \mathrm{~min}$ followed by vortexing for $30 \mathrm{~s}$. The reconstituted solvent phase was filtered through a $0.2-\mu \mathrm{m}$ nylon filter (SigmaAldrich). A 200- $\mu \mathrm{L}$ aliquot of the top layer of the reconstituted extract was transferred to a glass insert inside a 2-mL amber glass vial (Verex; Phenomenex Inc.) for ultra-performance liquid chromatography (UPLC) analysis. The concentration of retinyl palmitate (vitamin A) and vitamin $\mathrm{D}_{3}$ was measured by reverse-phase UPLC (Acquity H-Class; Waters Corp., Milford, MA) with photodiode array detection (325 $\mathrm{nm}$ for retinyl palmitate and $265 \mathrm{~nm}$ for vitamin $\mathrm{D}_{3}$ ) and an Acquity BEH C18 1.7- $\mu \mathrm{m}, 2.1-\times 50-\mathrm{mm}$ column. A methanol/ acetonitrile gradient (Sigma Aldrich) was used as the mobile phase. The concentration of retinyl palmitate $(\mu \mathrm{g} / \mathrm{mL})$ was calculated using a relative response factor determined with calibration standards $(0.05-5 \mu \mathrm{g} /$ $\mathrm{mL}$; purity $>99.8 \%$, Sigma-Aldrich). The concentration of vitamin $\mathrm{D}_{3}(\mu \mathrm{g} / \mathrm{mL})$ was calculated using a relative response factor determined with calibration standards (0.001-0.05 $\mu \mathrm{g} / \mathrm{mL}$; purity $>99.8 \%$, Sigma Aldrich).

Riboflavin Analysis. Riboflavin analysis was conducted in accordance with the procedure published by Silva et al. (2005). Briefly, $0.75 \mathrm{~mL}$ of $33 \%$ trichloroacetic acid (Sigma-Aldrich) was added to $0.5 \mathrm{~mL}$ of milk in a 2-mL Eppendorf tube (Sigma-Aldrich). Eppendorf tubes were vortexed for $30 \mathrm{~s}$ and centrifuged for $10 \mathrm{~min}$ at $10,000 \times g$ in a benchtop centrifuge. The supernatant was filtered through a $0.2-\mu \mathrm{m}$ nylon filter (F2513-2, Sigma-Aldrich) into a 2-mL amber HPLC vial for UPLC analysis. Reverse-phase chromatography with a Waters HSS C18 1.8- $\mu \mathrm{m}, 2.1-\times 100-\mathrm{mm}$ column and a mobile-phase gradient consisting of $100 \%$ methanol (Sigma-Aldrich) and $150 \mathrm{mmol}$ of dibasic potassium phosphate solution (adjusted to $\mathrm{pH} 7$ with phosphoric acid and filtered through a $0.2-\mu \mathrm{m}$ nylon filter; Sigma-Aldrich) was used to analyze samples. The concentration of riboflavin in milks was measured by UPLC (Acquity H-Class; Waters Corp.) with fluorescence detection using excitation at $420 \mathrm{~nm}$ and emission at $530 \mathrm{~nm}$. The concentration of riboflavin $(\mu \mathrm{g} /$ $\mathrm{mL}$ ) was calculated using a relative response factor determined with calibration standards $(0.10-3 \mu \mathrm{g} / \mathrm{mL}$; purity $97.3 \%$, Sigma-Aldrich).

Descriptive Analysis of Light-Exposed Milks. All sensory testing of milks was deemed exempt by the North Carolina State University Institutional Review Board for human subjects. Descriptive sensory analysis of milk flavor was conducted on milks using a trained descriptive sensory panel and an established milk flavor language (Croissant et al., 2007; McCarthy et al., 2017b). Descriptive analysis was conducted $3 \mathrm{~d}$ after processing, following the 24 -h equilibration period shielded from light and the 48-h period during which some of the samples were exposed to FL or LED light for $2,4,12,24$, or 48 h. Panelists ( $\mathrm{n}=8,6$ women, 2 men, ages 22-49 yr) each had more than $150 \mathrm{~h}$ of previous experience with the sensory analysis of food aromas and flavors using the Spectrum descriptive analysis method (Meilgaard et al., 2007). A total of 40 milks were evaluated in duplicate for each experimental replication: 10 light exposure treatments for each fortification treatment as well as unfortified milks (FL or LED for each vitamin premix for $0,4,12,24$, and 48 
h). Milks were dispensed $(60 \mathrm{~mL})$ directly into 3-digitcoded 120-mL lidded soufflé cups (Solo Cup Co.) for evaluation. Preparations were conducted with the overhead lights off to avoid exposure to light. Samples were evaluated by each panelist in duplicate in a randomized order with a 60-s enforced rest between samples, during which panelists were instructed to rinse and cleanse their palates with deionized water and unsalted saltine crackers. No more than 6 samples were evaluated in a session followed by a 30-min rest between sessions for each panelist. Sixteen sessions were conducted across 3 $\mathrm{d}$ to evaluate all samples. Compusense Cloud (Compusense Inc.) was used for data collection.

Volatile Compound Analysis of Light-Exposed Milks. Volatile compounds were extracted from lightexposed milks by headspace SPME followed by GC-MS analysis as described by Yeh et al. (2017a). All injections were made on an Agilent 7820 GC with a 5975 mass selective detector (Agilent Technologies Inc.) with a ZB5-ms (5\% phenyl-arylene stationary phase, $30 \mathrm{~m}$ long $\times 0.25 \mathrm{~mm}$ i.d. $\times 0.25 \mu \mathrm{m}$ film thickness, Zebron; Phenomenex Inc.). Samples were injected using a CTC Analytics CombiPal Autosampler. Five milliliters of milk and $20 \mu \mathrm{L}$ of internal standard solution (2-methyl3-heptanone in ether at $81 \mathrm{mg} / \mathrm{kg}$; Sigma-Aldrich) were added to 20-mL amber glass SPME vials (Microliter Analytical) in triplicate. Vials were equilibrated for $25 \mathrm{~min}$ at $40^{\circ} \mathrm{C}$ with 4 -s pulses of $250 \mathrm{rpm}$ agitation. A 1-cm SPME fiber (divinylbenzene/carboxen/ polydimethylsiloxane; Supelco) was used for all analyses. The SPME fiber was exposed to the samples for $40 \mathrm{~min}$ at a depth of $3.1 \mathrm{~cm}$. The fiber was retracted and injected at $5.0 \mathrm{~cm}$ in the $\mathrm{GC}$ inlet for $5 \mathrm{~min}$. A combination of scanning from 40 to $200 \mathrm{~m} / \mathrm{z}$ and selective ion mode for ions 56 (hexanal), 70 (heptanal), and 85 (2-methyl-3-heptanone internal standard) was performed to identify compounds of interest. Each milk sample was evaluated in triplicate.

Compounds previously identified in the literature to be related to light oxidation (hexanal and heptanal) were identified and quantified by relative abundance (Kim and Morr, 1996; van Aardt et al., 2005; Webster et al., 2009). Aldehydes such as hexanal and heptanal have the lowest sensory threshold of light-induced lipid oxidation volatiles, and as such are generally considered key markers for lipid oxidation in fluid milk (Marsili, 1999; Lee and Min, 2009). Hexanal and hexanal concentrations have been associated with light-oxidized flavor in fluid milk by various studies (Bassette, 1976; Marsili, 1999; Mestdagh et al., 2005; Lee and Min, 2009). MassHunter software (Agilent Technologies Inc.) was utilized. Compounds were verified using retention times and mass spectra of authentic standards. To calculate retention indices, an alkane series $\left(\mathrm{C}_{8}-\mathrm{C}_{20}\right.$, SigmaAldrich) was used (Van Den Dool and Kratz, 1963).

Solvent-Assisted Sorptive Stir Bar Extraction Analysis of Vitamin A-Fortified Milks. Previous results (Yeh et al., 2017a) as well as sensory and GC-O results from the current study suggested that flavors specific to vitamin A degradation were present in some of the vitamin A fortified milks with and without light exposure. Solvent-assisted sorptive stir bar extraction (SA-SBSE) analysis was used to detect and quantify aroma-active compounds related to vitamin degradation ( $\alpha$-phellandrene, $\beta$-cyclocitral, $\beta$-damascone, $\beta$-ionone, and $\alpha$-irone; Yeh et al., 2017a) in both water-dispersible and oil-based vitamin A-fortified milks (Ochiai et al., 2016). Each milk was evaluated in triplicate. Before analysis, $10 \times 0.5 \mathrm{~mm}$ polydimethylsiloxane (PDMS)coated magnetic stir bars and thermal desorption unit tubes (Gerstel Inc., Linthicum, MD) were conditioned for $1 \mathrm{~h}$ at $300^{\circ} \mathrm{C}$. Next, batches of 10 stir bars were submerged in $20 \mathrm{~mL}$ of cyclohexane $(99.9 \%$ purity, Sigma-Aldrich) for $30 \mathrm{~min}$. Bloat time was determined by bloating the stir bars in cyclohexane and weighing them periodically; the ideal bloat time was the time after which the stir bars no longer significantly increased in weight. One bloated stir bar was added to $10 \mathrm{~mL}$ of milk in a $10-\mathrm{mL}$ amber glass vial (Microliter Analytical) and rotated on a magnetic stir plate at $900 \mathrm{rpm}$ for $60 \mathrm{~min}$ at $25^{\circ} \mathrm{C}$. After sample extraction, stir bars were rinsed with HPLC-grade water (Fisher Scientific) and dried briefly.

An autosampler (MPS Autosampler, Gerstel Inc.) was used to desorb stir bars on a thermal desorption unit at $250^{\circ} \mathrm{C}$ for $10 \mathrm{~min}$. Volatile compounds were cryogenically trapped at $-120^{\circ} \mathrm{C}$ and analyzed using an Agilent 7890B series GC/Agilent inert 5977A MSD equipped with a ZB5-MS column (5\% phenyl stationary phase, $30 \mathrm{~m}$ length $\times 0.25 \mathrm{~mm}$ i.d. $\times 0.25 \mu \mathrm{m}$ film thicknes, Zebron; Phenomenex Inc.). Initial GC oven conditions were $40^{\circ} \mathrm{C}$ for $3 \mathrm{~min}$, increasing at $10^{\circ} \mathrm{C} /$ $\min$ to $90^{\circ} \mathrm{C}$, at $5^{\circ} \mathrm{C} / \mathrm{min}$ to $200^{\circ} \mathrm{C}$, held for $10 \mathrm{~min}$, and then increasing at $20^{\circ} \mathrm{C} / \mathrm{min}$ to $250^{\circ} \mathrm{C}$, and held for 5 min. Purge time was set to $1.2 \mathrm{~min}$ using helium as the carrier gas at a constant flow rate of $1 \mathrm{~mL} / \mathrm{min}$. A combination of scanning from 40 to $200 \mathrm{~m} / z$ and selective ion mode for ions 93 ( $\alpha$-phellandrene), 121 ( $\alpha$-irone), 137 ( $\beta$-cyclocitral), and 177 ( $\beta$-damascone, $\beta$-ionone) was performed to identify compounds of interest. Compounds were identified by comparison with the 2014 National Institute of Standards and Technology (NIST) mass spectral library (NIST, 2014) as well as by comparison with retention index and time of authentic standards injected under identical conditions. Concentration of selected vitamin degradation compounds 
( $\alpha$-phellandrene, $\beta$-cyclocitral, $\beta$-ionone, $\beta$-damascone, and $\alpha$-irone) was calculated using a relative response factor determined with calibration standards (0.05-200 ng/mL; Sigma-Aldrich).

\section{Statistical Analysis}

Data were analyzed as a split-plot experiment with fortification type as the whole-plot factor and duration of lighting as the sub-plot factor. A separate analysis was conducted for each type of lighting. Fixed effects in the model were fortification type, duration of lighting, and their interaction. Random effects included batch replication, fortification type $\times$ batch replication interaction, and duration of lighting $\times$ fortification type $\times$ batch replication interaction. For descriptive analysis data, fixed effects were fortification type, duration of lighting, and their interaction. Random effects were batch replication, panelist $\times$ batch replication interaction, fortification type $\times$ panelist $\times$ batch replication interaction, and duration of lighting $\times$ fortification type $\times$ panelist $\times$ batch replication interaction. All analyses were conducted with SAS software (version 9.4, SAS Institute Inc., Cary, NC).

\section{RESULTS AND DISCUSSION}

\section{Experiment 1}

Descriptive Analysis of Light-Exposed Vitamin Premixes. Sensory data were consistent with the findings of Yeh et al. (2017a). Higher overall aroma intensities were noted in water-dispersible premixes than in oil-soluble premixes for all time points and light types evaluated ( mean $=2.2$ vs. 2.7, respectively; $P=0.028$ ). Vitamin A premixes had higher overall aroma intensities than vitamin $\mathrm{D}$ premixes regardless of matrix, time, or light exposure (mean $=2.8$ vs. 2.1, respectively; $P<0.001$ ). Floral and carrot aromas were detected in both types (water-dispersible and oil-based) of vitamin A premixes (mean $=4.5$ and 4.0 for floral and carrot aromas in water-dispersible premixes and 3.0 and 3.5 in oil-based prefixes, respectively). Exposure to FL or LED light resulted in significant muting of the overall aroma of both types of vitamin A premixes after $4 \mathrm{~h}$ (mean $=3.0$ vs. 2.5 for oil-based; 4.5 vs. 2.5 for water-dispersible; $P=0.024$ ). Exposure of vitamin A oil premixes to FL resulted in development of a vinegar aroma $($ mean $=3.0)$ after $4 \mathrm{~h}$, which was not detected after exposure to LED light. Exposure to FL or LED light resulted in muting of the overall aroma in both types of vitamin D premixes after $8 \mathrm{~h}$ (mean $=2.4$ vs. 2.0 for oil-based; 2.5 vs. 2.0 for water-dispersible; $P=$ 0.031). The vinegar aroma detected in the oil-based vitamin A premixes following $4 \mathrm{~h}$ of $\mathrm{FL}$ light exposure was the only discernible sensory effect of light exposure other than overall decreases in aroma.

Instrumental Volatile Analysis. Instrumental results were similar to those noted by Yeh et al. (2017a). More aroma events were recorded for waterdispersible premixes than for oil-based premixes and for vitamin A premixes than for vitamin D premixes. Twenty-eight aroma-active compounds were detected in the vitamin premixes: 15 terpenes ( $\alpha$-phellandrene, limonene, $\beta$-damascone, $\beta$-ionone, $\beta$-ionone epoxide, dihydroactinidiolide, $\alpha$-irone, $\beta$-cyclohomocitral, $\alpha$-copaene, $\alpha$-pinene, 2-carene, isogeraniol, citronellal, $\beta$-cyclocitral, and isopulegol), 8 aldehydes [hexanal, heptanal, (E)-2-heptanal, octanal, (E)-2-octanal, (E)-2-nonanal, nonanal, and (E)-2-decanal], 1 ketone (6-methyl-5-heptenone), 1 fatty alcohol (1-octanol), and 3 hydrocarbons (3,7-dimethyl-1-octene, 1-dodecene, and dodecene; results not shown). The aroma-active compounds documented here were similar to those published in Yeh at al. (2017a) and included the key aroma compounds attributed to the floral and carroty aromas previously published by Yeh et al. (2017a).

No new compounds were detected in light-exposed premixes, which had not been detected in unexposed premixes. Volatile compounds in experiment 1 were not measured quantitatively because the purpose was to identify potential additional compounds formed during light exposure not found in light-shielded premixes to aid in signal searching during subsequent experiments. Sensory and instrumental data from experiment 1 suggested that changes in the aroma of light-exposed vitamin premixes were likely due to changes in the concentration of volatile compounds found in unexposed premixes rather than the formation of new compounds over the course of light exposure.

\section{Experiment 2}

Proximate Analysis of Pilot Plant Manufactured Skim Milk. Raw skim milk fat content was $<0.10 \%$ and TS content was $9.3 \pm 0.00 \%$ (wt/wt). Total plate counts and coliform plate counts in raw milks averaged $9 \times 10^{2} \mathrm{cfu} / \mathrm{mL}$ and $23 \mathrm{cfu} / \mathrm{mL}$, respectively. Somatic cell counts in raw milks were $<200,000$ cells/ $\mathrm{mL}$. Mean fat and TS contents of pasteurized fortified milks were $<0.10 \%$ and $9.2 \pm 0.1 \%$ (wt/wt), respectively. Alkaline phosphatase results indicated complete HTST pasteurization of all milks. No coliforms were detected in pasteurized milks, and total plate counts in pasteurized milks were less than $10^{2} \mathrm{cfu} / \mathrm{mL}$.

Vitamin Degradation. Vitamin A and D degradation were consistent with results from previous work (Renken and Warthesen, 1993; Whited et al., 2002). 
No significant vitamin D degradation was observed across the exposure period with either light type $(P>$ 0.05; results not shown). After $48 \mathrm{~h}$ of light exposure, vitamin A loss in water-dispersible fortified milk was $54 \pm 3 \%$ and $61 \pm 5 \%$ for LED- and FL-exposed milks, respectively (Figure 1). Vitamin A loss in oil-fortified milks was $37 \pm 5 \%$ and $45 \pm 2 \%$ for LED- and FLexposed milks, respectively (Figure 1). Vitamin A loss was higher in milks fortified with water-dispersible versus oil-based vitamin A $(P<0.001)$. These results are consistent with the findings of Brothersen et al. (2016), Whited et al. (2002), and Fellman et al. (1991). Native riboflavin in milks was also degraded following light exposure. After $48 \mathrm{~h}$ of light exposure, the percent loss of riboflavin was higher for FL-exposed than for LEDexposed milks ( $52 \pm 6 \%$ and $30 \pm 4 \%$, respectively), similar to the degradation observed in previous studies (Gaylord et al., 1986; Palanuk et al., 1988; Lee et al., 1998).

Descriptive Analysis of Light-Oxidized Milk. Typical HTST pasteurized milk flavors (cooked/milky, sweet aromatic, sweet taste, salty taste, astringency) did not change with storage time, fortification, or light exposure $(P>0.05$; results not shown $)$. Typical light oxidation flavors (cardboard, mushroom/serumy) were only detected in light-exposed milks. For cardboard and mushroom/serumy flavors, we detected a significant effect of time $(P<0.0001)$ but not of fortification or fortification $\times$ time, suggesting that fortification had no effect on the development of these typical light oxidation flavors. These flavors were not detected in milks unexposed to light. Both cardboard and mushroom/ serumy flavors increased with exposure to FL or LED light (Table 1). Brothersen et al. (2016) also reported greater sensory effects of light oxidation in FL-exposed milks compared with LED-exposed milks.

Significant effects were documented for fortification, time, and fortification $\times$ time for carrot and perfumey $/$ floral flavors (Figures 2 to 5). Carrot flavor was only detected in milks fortified with water-dispersible vitamin A premix, regardless of light exposure, consistent with the findings of Yeh et al. (2017a). Initial carrot flavor (mean $=1.1 \pm 0.2$ ) decreased with FL exposure to 0.5 after $48 \mathrm{~h}$ (Figure 2). Carrot flavor in waterdispersible vitamin A-fortified skim milk $($ mean $=1.1$ \pm 0.2 ) did not change following exposure to LED light $(P>0.05$; Figure 3$)$. Perfumey/floral flavor was detected only following light exposure in milks fortified with oil-based vitamin A premix. Initially, perfumey/ floral flavor was not detected in any of the skim milks. Intensities increased to mean values of $1.5 \pm 0.3$ and $0.5 \pm 0.2$ following exposure to FL or LED light, respectively (Figures 4 and 5).

$S P M E-G C$ - $M S$. Time was the only significant factor for concentrations of hexanal and heptanal $(P<$ 0.001 for all analyses); no significant interactions were

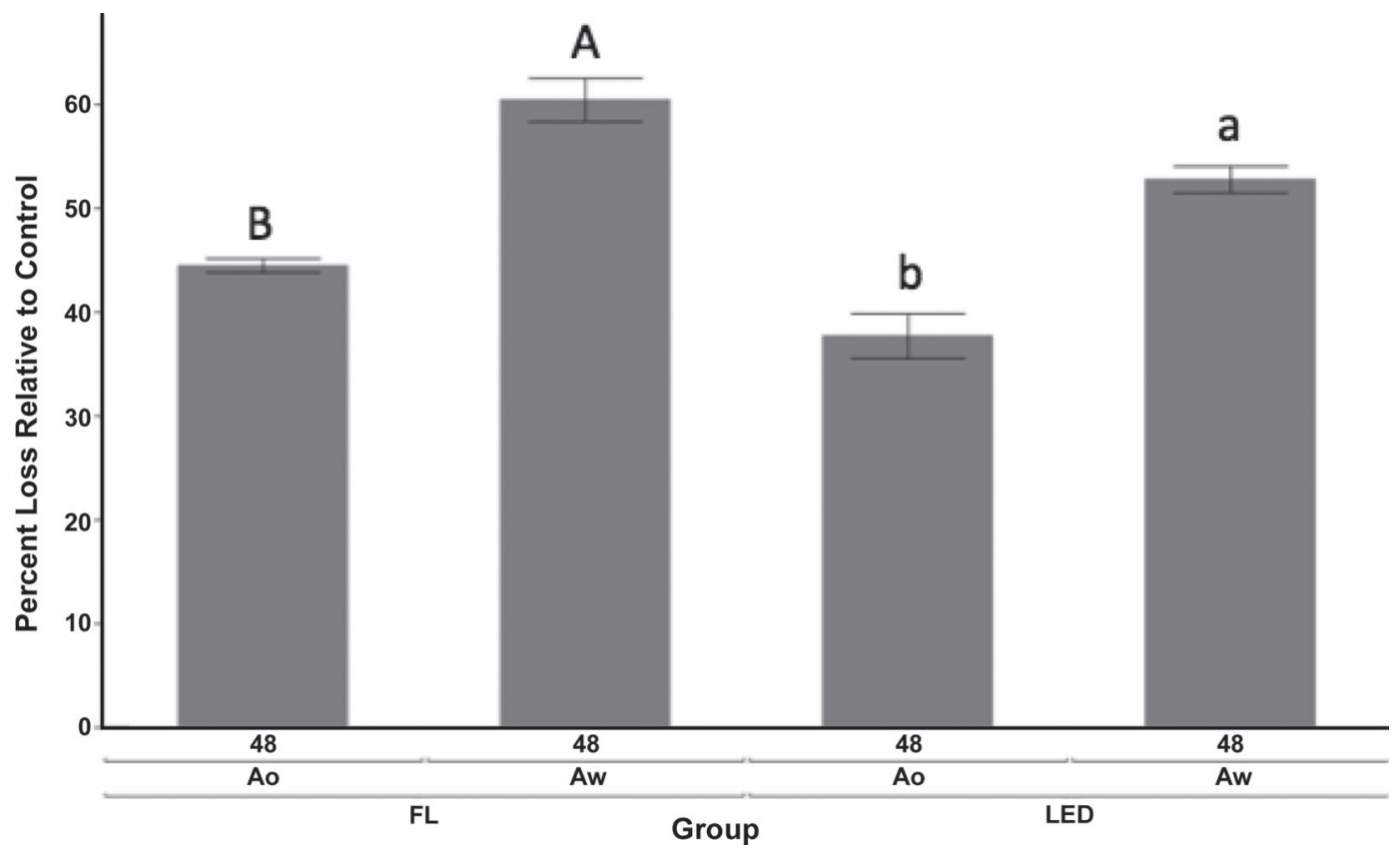

Figure 1. Vitamin A degradation (percent loss relative to control; means $\pm \mathrm{SE}$ ) in vitamin A-fortified light-exposed milks after $48 \mathrm{~h}$. Different letters indicate statistically significant percent losses $(P<0.05)$. Statistical comparisons are made within light type $($ fluorescent, FL, A vs. B; or light-emitting diode, LED, a vs. b). Aw = water-dispersible vitamin A-fortified milk, Ao = oil-based vitamin A-fortified milk. 


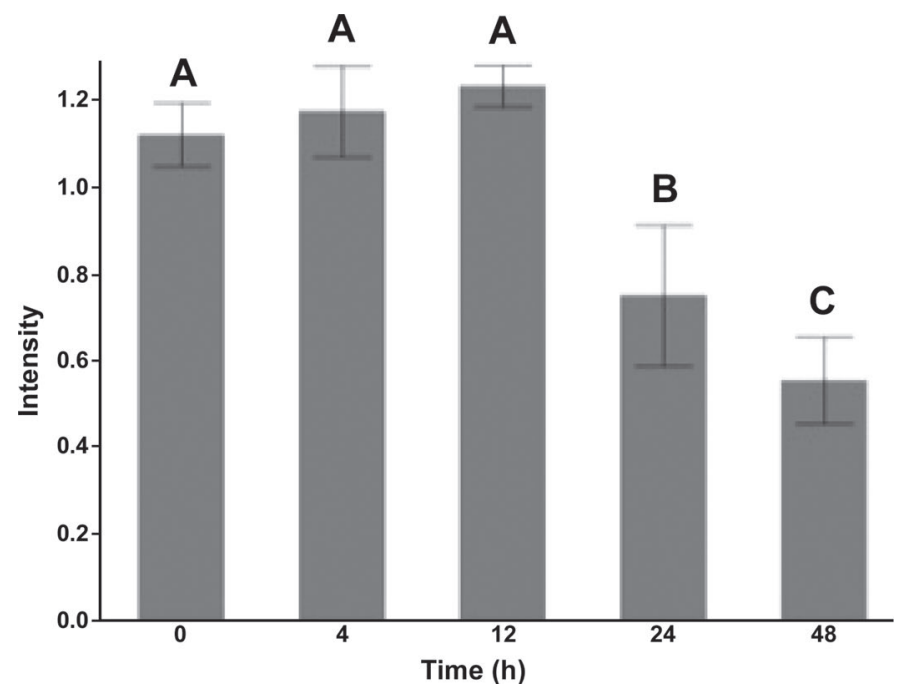

Figure 2. Carrot flavor intensity in water-based vitamin A-fortified skim milks exposed to fluorescent light across the 48-h light exposure time. Carrot flavor was scored on a 0 to 15 point universal Spectrum intensity scale. Most fluid milk flavors fall between 0 and 4 on this scale (Croissant et al., 2007; McCarthy et al., 2017b). Standard error bars are included. This flavor was only detected in skim milk fortified with water-dispersible vitamin A premix. Bars (light exposure times) with different letters $(\mathrm{A}-\mathrm{C})$ are significantly different $(P<0.05)$.

observed $(P>0.05$; Figures 6 and 7$)$. Fortification type had no effect on concentrations of hexanal or heptanal $(P>0.05)$, but exposure to FL or LED increased concentrations of these lipid oxidation compounds (Figures 6 and 7). Hexanal concentrations in milks stored at $4^{\circ} \mathrm{C}$

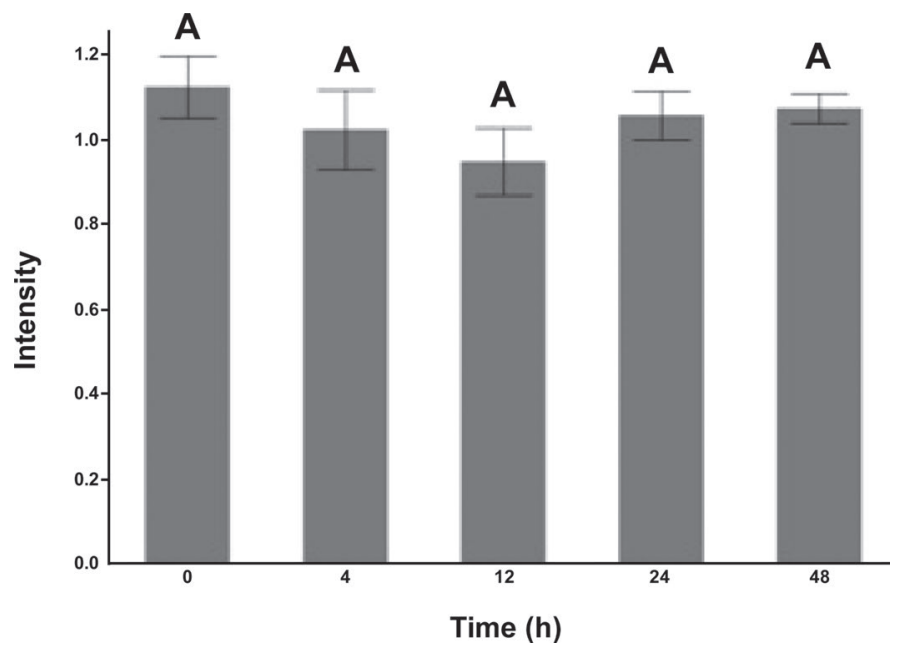

Figure 3. Carrot flavor intensity in water-based vitamin A-fortified skim milks exposed to light-emitting diode light across the 48-h light exposure time. Carrot flavor was scored on a 0 to 15 point universal Spectrum intensity scale. Most fluid milk flavors fall between 0 and 4 on this scale (Croissant et al., 2007; McCarthy et al., 2017b). Standard error bars are included. This flavor was only detected in skim milk fortified with water-dispersible vitamin A premix. Bars (light exposure times) that share a letter $(\mathrm{A})$ are not significantly different $(P>0.05)$.
Table 1. Trained panel light oxidized flavor intensities ${ }^{1}$ in skim milks exposed to fluorescent (FL) or light-emitting diode (LED) light

\begin{tabular}{llll}
\hline Time & Flavor & FL & LED \\
\hline $0 \mathrm{~h}$ & Cardboard & $\mathrm{ND}^{2}$ & $\mathrm{ND}$ \\
& Mushroom/Serumy & $\mathrm{ND}$ & $\mathrm{ND}$ \\
$4 \mathrm{~h}$ & Cardboard & $0.7^{\mathrm{D}}$ & $0.5^{\mathrm{D}}$ \\
& Mushroom/Serumy & $0.5^{\mathrm{c}}$ & $\mathrm{ND}$ \\
\multirow{2}{*}{$2 \mathrm{~h}$} & Cardboard & $1.2^{\mathrm{C}}$ & $1.1^{\mathrm{C}}$ \\
& Mushroom/Serumy & $0.5^{\mathrm{c}}$ & $\mathrm{ND}$ \\
& Cardboard & $1.6^{\mathrm{B}}$ & $1.3^{\mathrm{B}}$ \\
& Mushroom/Serumy & $1.0^{\mathrm{b}}$ & $0.6^{\mathrm{a}}$ \\
& Cardboard $\mathrm{h}$ & $2.6^{\mathrm{A}}$ & $1.9^{\mathrm{A}}$ \\
& Mushroom/Serumy & $1.7^{\mathrm{a}}$ & $0.7^{\mathrm{a}}$ \\
\hline
\end{tabular}

${ }^{\mathrm{a}-\mathrm{c}}$ Different lowercase letters following means in a column indicate statistical differences among time points for that flavor attribute and light type $(P<0.05)$.

${ }^{\mathrm{A}-\mathrm{D}}$ Different uppercase letters following means in a column indicate statistical differences among time points for that flavor attribute and light type $(P<0.05)$.

${ }^{1}$ Cardboard and mushroom/serumy flavors were scored on a 0 to 15 point universal Spectrum intensity scale. Most fluid milk flavors fall between 0 and 4 on this scale (Croissant et al., 2007; McCarthy et al., $2017 b$ ). Time was the only significant factor in the model; thus, averages of all fortification types for each time point are presented.

${ }^{2} \mathrm{ND}=$ not detected.

for $48 \mathrm{~h}$ in the dark were $26.3 \pm 3.2 \mu \mathrm{g} / \mathrm{L}$ compared with $136.1 \pm 11.0 \mu \mathrm{g} / \mathrm{L}$ for milks exposed to FL light for $48 \mathrm{~h}$ and $92.6 \pm 13.2 \mu \mathrm{g} / \mathrm{L}$ for milks exposed to LED light for $48 \mathrm{~h}$. Heptanal concentrations in milks

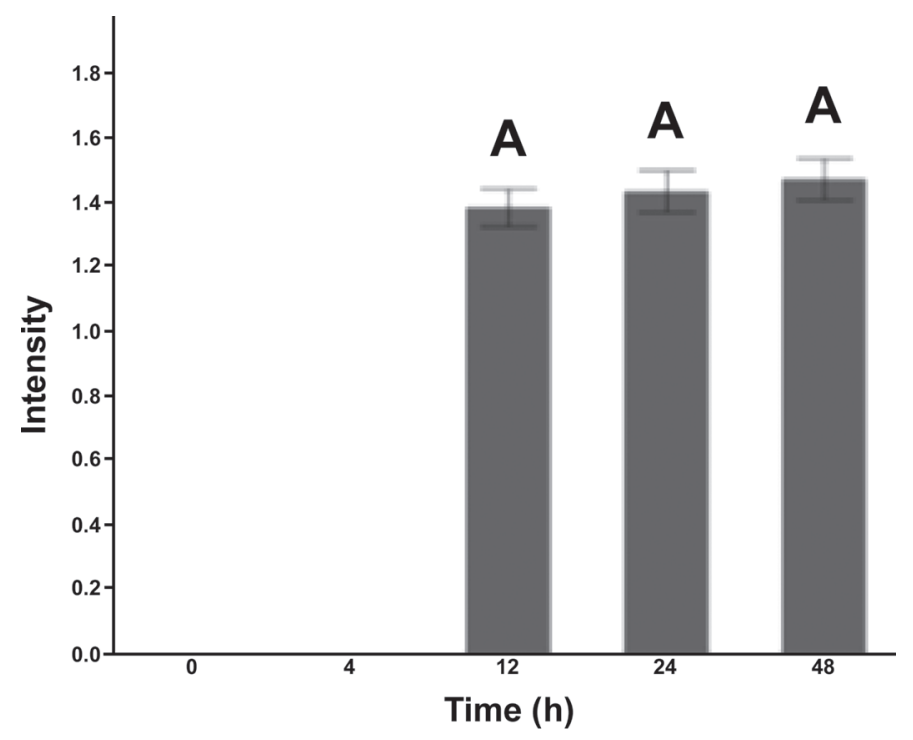

Figure 4. Perfumey/floral flavor in oil-based vitamin A-fortified skim milks exposed to fluorescent light. Perfumey/floral flavor was scored on a 0 to 15 point universal Spectrum intensity scale. Most fluid milk flavors fall between 0 and 4 on this scale (Croissant et al., 2007; McCarthy et al., 2017b). Standard error bars are included. This flavor was only detected in oil-based vitamin A-fortified skim milks following exposure to fluorescent light or light-emitting diode light. Bars (light exposure times) that share a letter (A) are not significantly different $(P>0.05)$. 
stored at $4^{\circ} \mathrm{C}$ for $48 \mathrm{~h}$ in the dark were $4.3 \pm 2.5 \mu \mathrm{g} / \mathrm{L}$ compared with $23.0 \pm 5.8 \mu \mathrm{g} / \mathrm{L}$ for milks exposed to FL light for $48 \mathrm{~h}$ and $12.8 \pm 4.1 \mu \mathrm{g} / \mathrm{L}$ for milks exposed to LED light for $48 \mathrm{~h}$.

$S A-S B S E$. Selected vitamin degradation compounds were detected in milks fortified with either oil-based or water-dispersible vitamin A but not in unfortified milks (Figure 8). Concentrations of vitamin degradation volatiles were not consistently different in oil-based or water-dispersible vitamin A-fortified milks $(P>0.05)$. The $P$-values for all compounds are shown in Table 2.

LED-Exposed Milks. $\alpha$-Phellandrene, $\beta$-damascone, and $\alpha$-irone concentrations were not affected by fortification or exposure duration $(P>0.05)$. $\beta$-Ionone was the only compound for which time was a significant factor $(P=0.0270)$. A significant fortification $\times$ time interaction was observed for $\beta$-cyclocitral $(P=0.0220)$ and $\beta$-ionone $(P=0.0418$; Figure 8$)$.

FL-Exposed Milks. $\alpha$-Phellandrene concentrations were not affected by fortification or exposure duration $(P>0.05)$. Time was a significant factor for $\beta$-cyclocitral, $\beta$-damascone, and $\alpha$-irone $(P<0.0001$, 0.0062 , and 0.0032 , respectively). A significant fortification $\times$ time interaction was observed for $\beta$-cyclocitral, $\beta$-damascone, and $\beta$-ionone $(P<0.0001,0.0161$, and 0.0064 , respectively; Figure 8). $\beta$-Damascone levels increased at $12 \mathrm{~h}$ for oil-based vitamin A-fortified milks and at $4 \mathrm{~h}$ for water-dispersible vitamin A-fortified

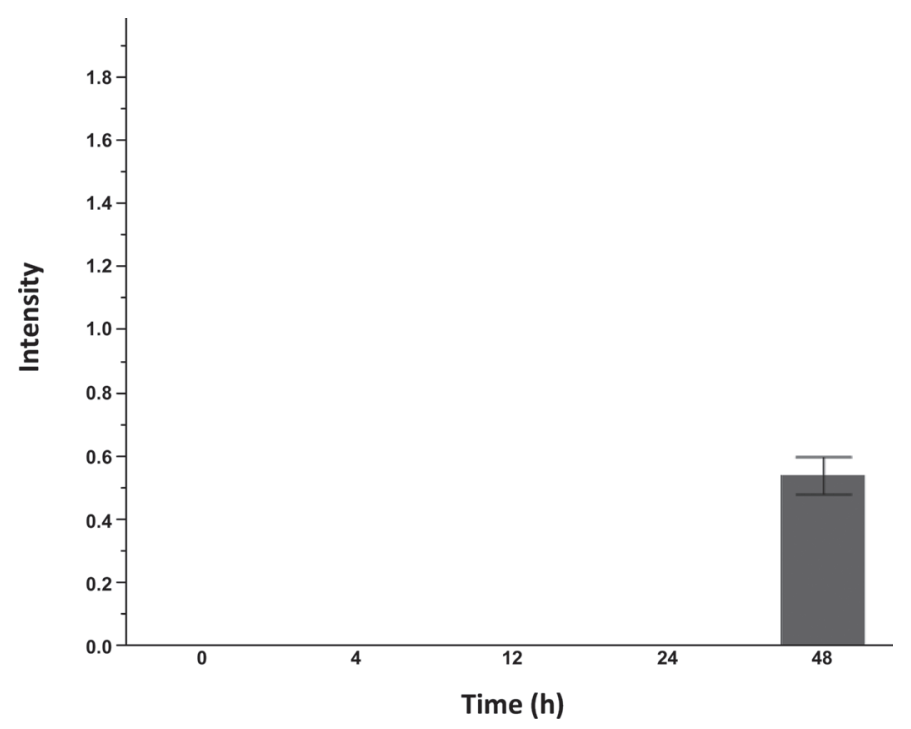

Figure 5. Perfumey/floral intensity in water-based vitamin A-fortified skim milks exposed to light-emitting diode light across the 48-h light exposure time. Perfumey/floral flavor was scored on a 0 to 15 point universal Spectrum intensity scale. Most fluid milk flavors fall between 0 and 4 on this scale (Croissant et al., 2007; McCarthy et al., 2017b). Standard error bars are included. This flavor was only detected in oil-based vitamin A-fortified skim milks following exposure to fluorescent light or light-emitting diode light.

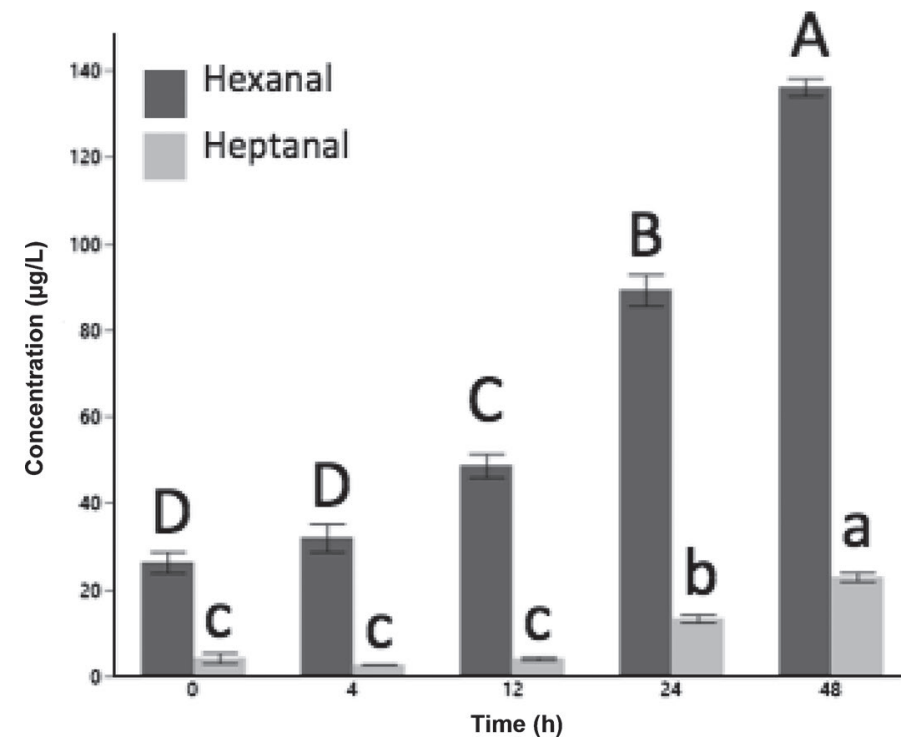

Figure 6. Average hexanal and heptanal concentrations in skim milks exposed to fluorescent light. Data are presented as an average across all treatments as no significant differences among treatments were identified $(P>0.05)$. Standard error bars are included. Different uppercase letters (A-D) indicate differences in hexanal concentration $(P<0.05)$. Different lowercase letters $(\mathrm{a}-\mathrm{c})$ indicate differences in heptanal concentration $(P<0.05)$. Different letters (uppercase or lowercase) indicate differences within that compound $(P<0.05)$.

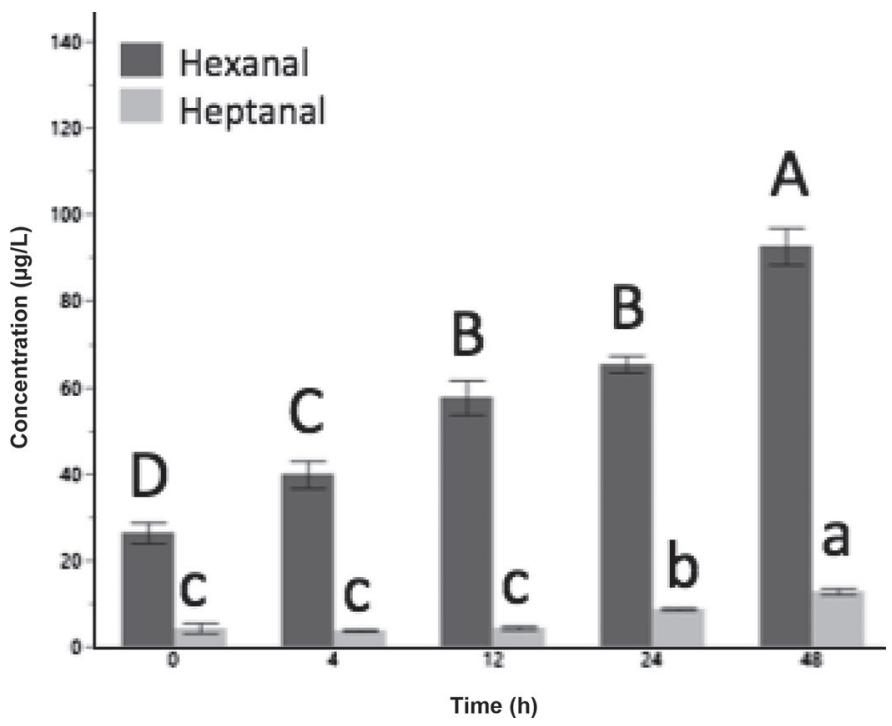

Figure 7. Average hexanal and heptanal concentrations in skim milks exposed to light-emitting diode light. Data are presented as an average across all treatments as no significant differences were identified among treatments $(P>0.05)$. Standard error bars are included. Different uppercase letters (A-D) indicate differences in hexanal concentration $(P<0.05)$. Different lowercase letters $(\mathrm{a}-\mathrm{c})$ indicate differences in heptanal concentration $(P<0.05)$. Different letters (uppercase or lowercase) indicate differences within that compound $(P$ $<0.05)$. 
Oil-Based Vitamin A Fortified

Water-Dispersible Vitamin A Fortified

Average

Beta-Cyclocitral

FL

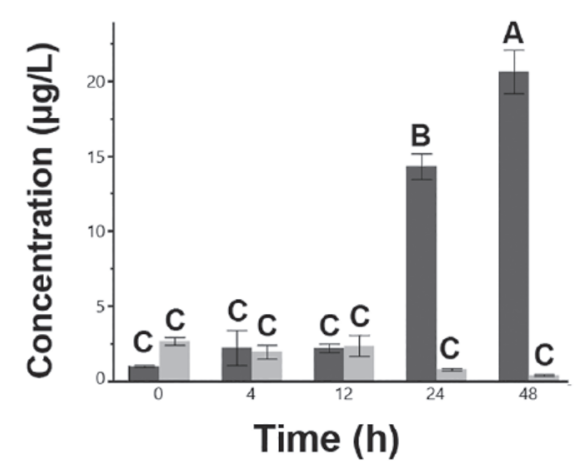

Beta-Ionone

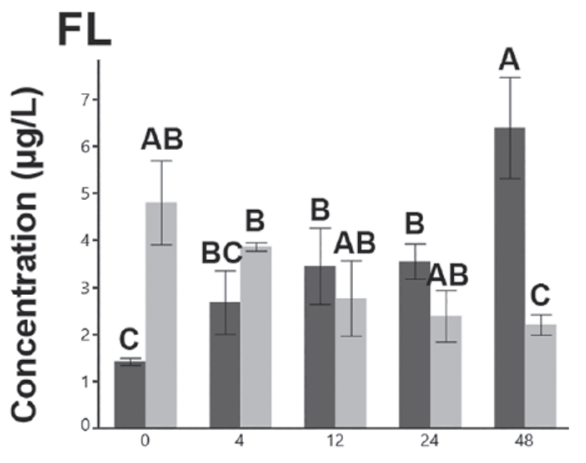

Time (h)

\section{Beta-Damascone}

FL

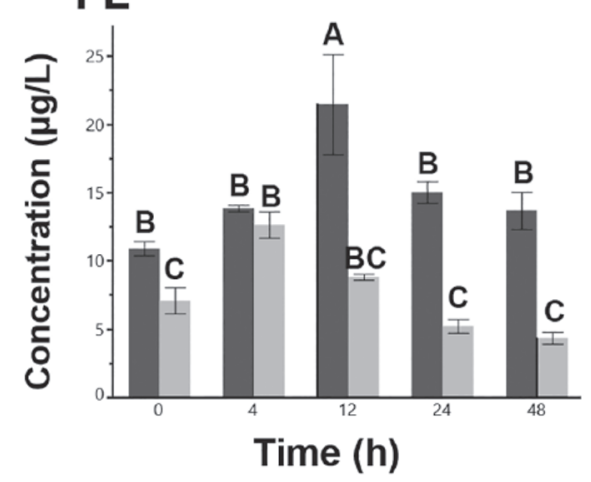

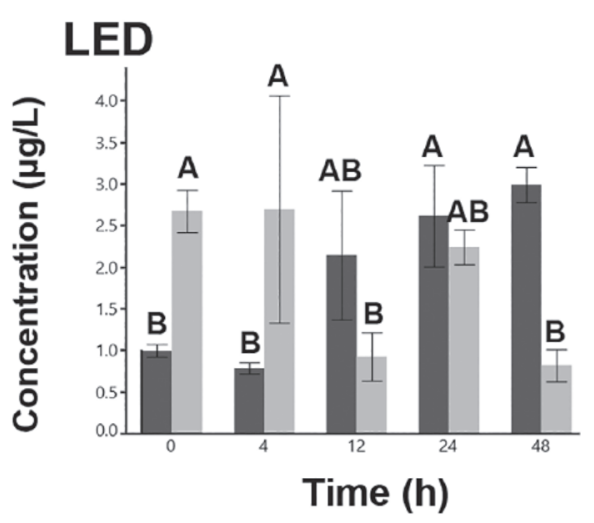

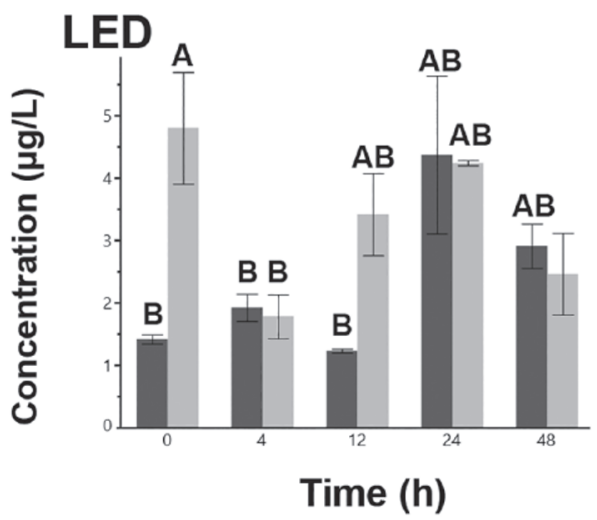

Alpha-Irone

FL

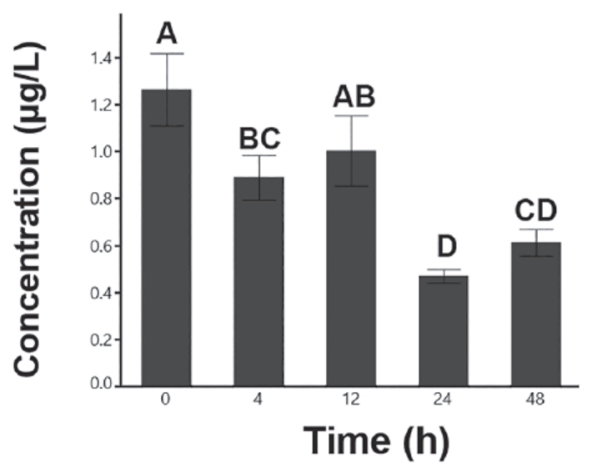

Figure 8. Selected aroma-active vitamin degradation compounds in vitamin A-fortified skim milks exposed to fluorescent light (FL; left panels) or light-emitting diode (LED; right panels) light. Standard error bars are included. Results are presented for specific volatile compounds for which significant effects were documented (Table 2). Bars (timepoints) with different letters (A-D) for each compound indicate significant differences $(P<0.05)$. 
Table 2. $P$-values associated with analysis of concentrations of vitamin degradation-related volatile compounds after exposure to light-emitting diode (LED) or fluorescent (FL) light

\begin{tabular}{lccccc}
\hline Item & $\alpha$-Phellandrene & $\beta$-Cyclocitral & $\beta$-Damascone & $\beta$-Ionone & $\alpha$-Irone \\
\hline LED & 0.4226 & 0.9459 & 0.1927 & 0.2361 & 0.5590 \\
$\quad$ Fortification & 0.2876 & 0.5949 & 0.8924 & 0.0270 & 0.1548 \\
Time & 0.0719 & 0.0220 & 0.4992 & 0.0418 & 0.1616 \\
$\quad$ Fortification $\times$ Time & 0.2374 & 0.0513 & 0.0742 & 0.6246 & 0.9463 \\
FL & 0.2323 & $<0.0001$ & 0.0062 & 0.3841 & 0.0032 \\
$\quad$ Fortification & 0.2323 & $<0.0001$ & 0.0161 & 0.0064 & 0.1097 \\
Time & & & & & \\
Fortification $\times$ Time & & & & & \\
\hline
\end{tabular}

milks, but then decreased across the remainder of the exposure period. $\beta$-Cyclocitral and $\beta$-ionone levels increased in oil-based vitamin A-fortified milks with light exposure but did not change in water-dispersible vitamin A-fortified milks. This result follows the trend observed for vitamin degradation off-flavors in vitamin A-fortified milks: perfumey/floral off-flavor increased in oil-based vitamin A-fortified milks with FL exposure, but was not detected in water-dispersible vitamin Afortified milks.

Although we did not directly compare FL and LED light-exposed milks in this study, light exposure to FL resulted in more significant changes in vitamin degradation-related volatiles than exposure to LED light. Vitamin fortification had no effect on development of typical light oxidation-related off-flavors (cardboard and mushroom/serumy), providing no evidence that vitamin fortification has any effect on light oxidation flavors. Vitamin D in oil-based or water-dispersible form did not contribute detectable off-flavors to skim milk regardless of light exposure, consistent with previous studies (Yeh et al., 2017a). However, the development of perfumey/floral flavor in the oil-based vitamin A-fortified milk and the decrease in intensity of carrot flavor in the water-dispersible vitamin A-fortified milk suggests that light exposure affected the specific offflavors contributed by vitamin A fortification.

Our statistical model did not directly compare FLand LED-exposed fortified milks but differences were noted in the levels of carrot and perfumey/floral flavors between the vitamin A-fortified milks exposed to the 2 light sources. Perfumey/floral flavor in oil-based vitamin A-fortified milks took longer to develop with exposure to LED than to FL (48 vs. $12 \mathrm{~h}$, respectively). Carrot flavor intensity did not change during LED exposure but decreased with FL exposure. The decrease may be due to further degradation of the aroma-active vitamin A degradation compounds presumed to cause this flavor or due to other oxidation-related flavors increasing and thus decreasing the sensory perception of the carrot flavor. Cardboard and mushroom/serumy off-flavors developed faster after exposure to FL com- pared with LED light for all fortification types (4 vs. $12 \mathrm{~h}$, respectively). Previous studies have demonstrated that FL exposure is more destructive to milk vitamin content and flavor (Brothersen et al., 2016).

Hexanal and heptanal are 2 volatile compounds indicative of lipid oxidation in fluid skim milk. Lipid oxidation is a part of light oxidation milk chemistry and, as expected, these compounds were higher in lightexposed milks than in unexposed milks. Fortification had no effect on hexanal and heptanal concentrations, showing no evidence that vitamin fortification has any protective effect on formation of light oxidation-related volatiles. Like sensory perception of light-oxidized flavors, hexanal and heptanal concentrations were higher after $48 \mathrm{~h}$ of exposure for FL-exposed milks than for LED-exposed milks, consistent with previous studies (Brothersen et al., 2016).

Aroma-active volatile vitamin A degradation compounds with carrot and floral aromas were detected in vitamin A-fortified skim milks but not unfortified controls (Figure 8). Each of the selected compounds behaved differently when exposed to light in skim milk, indicating that the mechanisms surrounding formation of aroma-active vitamin A degradation volatiles are complex and heavily influenced by light type and matrix. Furthermore, many degradation products of vitamin A are also light sensitive (Ly et al., 2008; Uriarte et al., 2018); thus, aroma-active compounds formed with light exposure could subsequently break down with additional light exposure into low levels of additional compounds, at or below limits of detection, further confounding the analysis of these compounds. More changes in concentrations of these volatiles were noted for samples exposed to FL light than to LED light, which could perhaps be another demonstration of the more damaging effects of FL light on milk and its components compared with LED light. Vitamin A and other carotenoids have demonstrated antioxidant capacities in other systems, but there is no evidence that vitamin fortification provides any protection against light oxidation off-flavors in fluid milk. Although increasing the concentration of vitamin A might offer 
a protective effect, increasing the fortification level of vitamin $\mathrm{A}$ in fluid milk is not recommended because of the potential toxicity of high levels of vitamin A (Institute of Medicine, 2000).

\section{CONCLUSIONS}

Off-flavors - flavors that do not naturally occur in fresh, quality milk and thus may be objectionable to consumers - were documented in skim milk fortified with water-dispersible vitamin A, consistent with previous studies. We found no evidence for an effect of vitamin fortification on development of typical light oxidation-related off-flavors, riboflavin degradation, or development of lipid oxidation-related volatiles. A newly documented perfumey/floral flavor was documented in oil-based vitamin A-fortified milk following light exposure, which may suggest that light exposure affects the specific off-flavors contributed by vitamin A fortification. These results demonstrate that the dairy industry should exercise care when selecting vitamin A premixes for milk fortification.

\section{ACKNOWLEDGMENTS}

Funding was provided in part by the National Dairy Council (Rosemont, IL). The use of trade names does not imply endorsement or lack of endorsement of those not mentioned.

\section{REFERENCES}

Airado-Rodríguez, D., N. Intawiwat, J. Skaret, and J. P. Wold. 2011. Effect of naturally occurring tetrapyrroles on photooxidation in cow's milk. J. Agric. Food Chem. 59:3905-3914.

Bassette, R. 1976. Effects of light on concentrations of some volatile materials in milk. J. Milk Food Technol. 39:10-12.

Bray, S. L., A. H. Duthie, and R. P. Rogers. 1977. Consumers can detect light-induced flavor in milk. J. Food Prot. 40:586-587.

Brothersen, C., D. J. McMahon, J. Legako, and S. Martini. 2016. Comparison of milk oxidation by exposure to LED and fluorescent light. J. Dairy Sci. 99:2537-2544.

Chang, A. C., and R. Dando. 2018. Exposure to light-emitting diodes may be more damaging to the sensory properties of fat-free milk than exposure to fluorescent light. J. Dairy Sci. 101:154-163.

Chen, Y., R. M. Reddy, W. Li, R. R. Yettlia, S. Lopez, and M. Woodman. 2015. Development and validation of a high performance liquid chromatographic method for simultaneous determination of vitamins A and D3 in fluid milk products. J. AOAC Int. 98:390-396.

Croissant, A. E., S. P. Washburn, L. L. Dean, and M. A. Drake. 2007. Chemical properties and consumer perception of fluid milk from conventional and pasture-based production systems. J. Dairy Sci. 90:4942-4953.

De Man, J. M. 1978. Prevention of light-induced quality loss in milk. J. Inst. Can. Sci. Technol. Aliment. 11:152-154.

DPC (Dairy Practices Council). 2001. DPC 53: Guidelines for vitamin A \& D fortification of fluid milk. 2001 Revision. The Dairy Practices Council, Keyport, NJ. Accessed May 18, 2018. https://www .dairypc.org/catalog/vitamin-a-and-d-fortification-of-fluid-milk.
Fellman, R. L., P. S. Dimick, and R. Hollander. 1991. Photooxidative stability of vitamin A fortified $2 \%$ lowfat and skim milk. J. Food Prot. 54:113-116.

Gaylord, A. M., J. J. Warthesen, and D. E. Smith. 1986. Influence of milk fat, milk solids, and light intensity on the light stability of vitamin A and riboflavin in lowfat milk. J. Dairy Sci. 69:2779-2784.

Gutierrez, A. M., T. D. Boylston, and S. Clark. 2018. Effects of prooxidants and antioxidants on the total antioxidant capacity and lipid oxidation products of milk during refrigerated storage. J. Food Sci. 83:275-283.

Institute of Medicine. 2000. Dietary Reference Intakes for Vitamin A, Vitamin K, Arsenic, Boron, Chromium, Copper, Iodine, Iron, Manganese, Molybdenum, Nickel, Silicon, Vanadium, and Zinc. National Academies Press, Washington, DC

IDFA (International Dairy Foods Association). 2016. Dairy Facts. IDFA, Washington, DC.

Johnson, D. S., S. E. Duncan, L. M. Bianchi, H. H. Chang, W. N. Eigel, and S. F. O'Keefe. 2015. Packaging modifications for protecting flavor of extended-shelf-life milk from light. J. Dairy Sci. 98:2205-2214

Kim, Y. D., and C. V. Morr. 1996. Dynamic headspace analysis of light activated flavor in milk. Int. Dairy J. 6:185-193.

Lee, K. H., M. Y. Jung, and S. Y. Kim. 1998. Effects of ascorbic acid on the light-induced riboflavin degradation and color changes in milk. J. Agric. Food Chem. 46:407-410.

Lee, J. H., and D. B. Min. 2009. Changes of headspace volatiles in milk with riboflavin photosensitization. J. Food Sci. 74:C563-568.

Ly, M. H., L. C. Hoang, J. M. Belin, and Y. Waché. 2008. Improved co-oxidation of beta-carotene to beta-ionone using xanthine oxidase-generated reactive oxygen species in a multiphasic system. Biotechnol. J. 3:220-225.

Marsili, R. T. 1999. Comparison of solid-phase microextraction and dynamic headspace methods for the gas chromatographic-mass spectrometric analysis of light-induced lipid oxidation products in milk. J. Chromatogr. Sci. 37:17-23.

Martin, N., N. Carey, S. Murphy, D. Kent, J. Bang, T. Stubbs, M. Wiedmann, and R. Dando. 2016. Exposure of fluid milks to LED light negatively affects consumer perception and alters underlying sensory properties. J. Dairy Sci. 99:4309-4324.

McCarthy, K. S., K. Lopetcharat, and M. A. Drake. 2017b. Milk fat threshold determination and the effect of milk fat content on consumer preference for fluid milk. J. Dairy Sci. 100:1702-1711.

McCarthy, K. S., M. Parker, A. Ameerally, S. L. Drake, and M. A. Drake. 2017a. Drivers of choice for fluid milk versus plant based alternatives: What are consumer perceptions of fluid milk? J. Dairy Sci. 100:6125-6138.

Meilgaard, M. C., G. V. Civille, and B. T. Carr. 2007. Descriptive analysis techniques. Pages 189-253 in Sensory Evaluation Techniques. 2nd ed. CRC Press, Boca Raton, FL.

Mestdagh, F., B. De Meulenaer, J. De Clippeleer, F. Devlieghere, and A. Huyghebaert. 2005. Protective influence of several packaging materials on light oxidation of milk. J. Dairy Sci. 88:499-510.

Min, D. B., and J. M. Boff. 2002. Chemistry and reaction of singlet oxygen in foods. Compr. Rev. Food Sci. Food Saf. 1:58-72.

NIST. 2014. NIST 14 mass spectral library. FarHawk Marketing Services, Evans Mills, NY.

Ochiai, N., K. Sasamoto, F. David, and P. Sandra. 2016. Solventassisted stir bar sorptive extraction by using swollen polydimethylsiloxane for enhanced recovery of polar solutes in aqueous samples: Application to aroma compounds in beer and pesticides in wine. J. Chromatogr. A 1455:45-56.

Palace, V. P., N. Khaper, Q. Qin, and P. K. Singal. 1999. Antioxidant potentials of vitamin $\mathrm{A}$ and carotenoids and their relevance to heart disease. Free Radic. Biol. Med. 26:746-761.

Palanuk, S. L., J. J. Warthesen, and D. E. Smith. 1988. Effect of agitation, sampling location and protective films on light-induced riboflavin loss in skim milk. J. Food Sci. 53:436-438.

PHS/FDA (Public Health Service/Food and Drug Administration). 2015. Grade "A" Pasteurized Milk Ordinance. US Government Printing Office, Washington, DC. 
Potts, H. L., K. N. Amin, and S. E. Duncan. 2017. Retail lighting and packaging influence consumer acceptance of fluid milk. J. Dairy Sci. 100:146-156.

Public Health Service. 1940. Milk ordinance and code, recommended by the US Public Health Service, 1939. Public Health Bulletin No. 220. US Government Printing Office, Washington, DC.

Renken, S. A., and J. J. Warthesen. 1993. Vitamin D stability milk. J. Food Sci. 3:552-556.

Rodriguez-Amaya, D. B. 2016. Natural food pigments and colorants. Curr. Opin. Food Sci. 7:20-26.

Silva, L. S., M. G. Trevisan, S. Rath, R. J. Poppi, and F. G. R. Reyes 2005. Chromatographic determination of riboflavin in the presence of tetracyclines in skimmed and full cream milk using fluorescence detection. J. Braz. Chem. Soc. 16:1174-1178.

Uriarte, I., S. Melandri, A. Maris, C. Calabrese, and E. J. Cocinero. 2018. Shapes, dynamics, and stability of $\beta$-ionone and its two mutants evidenced by high-resolution spectroscopy in the gas phase. J. Phys. Chem. Lett. 9:1497-1502.

van Aardt, M., S. E. Duncan, J. E. Marcy, T. E. Long, and S. F. O. Keefe. 2005. Aroma analysis of light-exposed milk stored with and without natural and synthetic antioxidants. J. Dairy Sci. 88:881890.

Van Den Dool, H., and P. Kratz. 1963. A generalization of the retention index system including linear programmed gas liquid partition chromatography. J. Chromatogr. 11:463-471.
Walsh, A. M., H. Potts, and S. Duncan. 2015. Comparing quality and emotional responses as related to acceptability of light induced oxidation flavor in milk. Food Res. Int. 76:293-300.

Webster, J. B., S. E. Duncan, J. E. Marcy, and S. F. O'Keefe. 2009. Controlling light oxidation flavor in milk by blocking riboflavin excitation wavelengths and interference. J. Food Sci. 74:S390-S398.

Wehr, H. M., and J. F. Frank, ed. 2004. Standard Methods for the Examination of Dairy Products. 17th ed. Am. Publ. Health Assoc. Inc., Washington, DC.

White, C. H., and M. Bulthaus. 1982. Light activated flavor in milk. J. Dairy Sci. 65:489-494.

Whited, L. J., B. Hamond, K. Chapman, and K. J. Boor. 2002. Vitamin A degradation and light-oxidized flavor defects in milk. J. Dairy Sci. 85:351-354.

Wold, J. P., J. Skaret, and T. K. Dalsgaard. 2015. Assessment of the action spectrum for photooxidation in full fat bovine milk. Food Chem. 179:68-75.

Yeh, E. B., D. M. Barbano, and M. A. Drake. 2017b. Vitamin fortification of fluid milk. J. Food Sci. 82:856-864.

Yeh, E. B., A. N. Schiano, Y. Jo, D. M. Barbano, and M. A. Drake. 2017a. The effect of vitamin concentrates on the flavor of pasteurized fluid milk. J. Dairy Sci. 100:4335-4348. 